\title{
PENGARUH MOTIVASI, KEPUASAN KERJA, DAN STRES KERJA TERHADAP KINERJA KARYAWAN PT TOYOTA AGUNG AUTOMALL BENGKULU
}

\author{
Rendy Alpahrasy \\ Nasution \\ Program Studi Manajemen Fakultas Ekonomi dan Bisnis \\ Universitas Bengkulu
}

\begin{abstract}
The purpose of this study is know that a influence of motivation, job satisfaction, and work stress on employee's performance of PT. Toyota Agung Automall Bengkulu. The subject of this study are employee who have worked on PT Toyota Agung Automall Bengkulu. Data were collected via questionnaires. 175 effective samples were collected to verify the hypotheses of this study. For data analysis and hypotheses testing, multiple linier regresion techinque was used. Sampling techinique in this study using census method. The result show that a motivation and job satisfaction have a positive and significant effect on employee performance, and work stress is significantly effect on employee performance.
\end{abstract}

Keywords: motivation, stress, performance.

\section{PENDAHULUAN}

\section{Latar Belakang}

Karyawan memiliki peranan penting dan sangat menentukan dalam suatu organisasi. Karyawan merupakan aset perusahaan yang sangat berharga dan harus dikelola dengan baik oleh perusahaan agar karyawan memiliki kinerja yang tinggi dan mampu membantu perusahaan untuk mencapai tujuannya. Hameed dan Waheed (2011:228) mengatakan bahwa karyawan memiliki peran yang sangat penting dalam kesuksesan sebuah organisasi karena tolok ukur keberhasilan organisasi dapat dilihat dari kinerja karyawannya. Menurut Hasibuan (2013:141), kinerja merupakan suatu hasil kerja yang dicapai seseorang dalam melaksanakan tugas-tugas yang dibebankan kepadanya yang didasarkan atas kecakapan, pengalaman dan kesungguhan serta waktu. Rivai dan Sagala (2011:548) mengatakan kinerja merupakan suatu hal yang sangat penting dalam upaya perusahaan untuk mencapai tujuannya. Faktor penting untuk membantu karyawan mengoptimalkan kinerjanya yaitu motivasi. Motivasi memainkan peranan penting karena merupakan hal yang menyebabkan, menyalurkan, dan mendukung perilaku manusia, supaya giat bekerja dan antusias mencapai hasil yang optimal (Hasibuan, 2013:141). Luthans dan Sommers (2005) mengemukakan bahwa motivasi adalah proses yang memberikan energi, mengubah sikap dan mempertahankan perilaku yang baik serta meningkatkan kinerja. Kepuasan kerja juga mendapat perhatian khusus bagi perusahaan karena berpengaruh terhadap kinerja karyawan itu sendiri. 
Velnampy (2008) menyimpulkan bahwa kepuasan kerja berpengaruh positif terhadap kinerja karyawan seperti meningkatnya keterlibatan kerja dan kinerja yang lebih tinggi, serta lebih berkomitmen untuk organisasi. Shahu dan Gole (2008) mengatakan bahwa ada efek dari pengaruh kepuasan kerja terhadap kinerja, maka dari itu kepuasan kerja harus dipertimbangkan oleh organisasi sebagai rencana penting dalam rangka meningkatkan kinerja karyawan, dan jika kepuasan kerjakaryawan rendah maka kinerja karyawan cenderung menurun. Ahmed dan Ramzan (2013:64)menjelaskan bahwa faktor lain yang perlu dipertimbangkan dalam rangka pengaruhnya terhadap kinerja adalah stress kerja. Stres dengan tingkat yang tinggi atau tingkat yang rendah secara berkelanjutan menyebabkan penurunan kinerja karyawan dan memerlukan aksi dari manajemen.

\section{Permasalahan Dan Lingkup Penelitian}

Hasil pra survei di PT Toyota Agung Automall Bengkulu menunjukkan masih adanya kendala mengenai motivasi karyawan. Atasan kurang memberikan semangat atau memberikan semacam motivasi terhadap bawahannya serta kurang mendukung bawahan dalam mengerjakan tugasnya. Selanjutnya, karyawan masih memiliki kendala mengenai kepuasan kerja. Rekan kerja sulit diajak bekerjasama dan berdiskusi karena masalah persaingan yang terjadi. Rekan kerja dari karyawan tersebut menganggap karyawan itu sebagai gangguan dan ancaman padahal mereka hanya ingin sharing seputar pekerjaan dan meminta solusi untuk menyelesaikan pekerjaan yang agak sulit untuk dikerjakan. Karyawan pada akhirnya merasa tidak nyaman dengan rekan kerja sendiri sehingga menimbulkan rasa canggung disaat mereka ingin berkomunikasi dan mengakibatkan karyawan-karyawan tersebut agak kecewa dan tidak puas dengan kondisi seperti ini. Karyawan di perusahaan ini mulai mengalami gejala-gejala stres seperti mengalami sakit kepala disaat pekerjaan mereka yang menumpuk dan ini terjadi secara terus-menerus. Karyawan juga mengalami kesulitan untuk tidur karena memikirkan beban kerja yang berat dan sebagian yang lain ada yang melamun serta tidak fokus disaat bekerja karena disebabkan pekerjaan yang menumpuk disertai dengan masalah-masalah diluar pekerjaan yang melanda mereka.

\section{TINJAUAN PUSTAKA}

\section{Kinerja}

Menurut Hameed dan Waheed (2011:228), kinerja karyawan adalah produktivitas dan output karyawan sebagai hasil dari pengembangan karyawan, dan akhirnya akan mempengaruhi efektivitas organisasi. Ahmed dan Ramzan (2013:65) mengatakan bahwa kinerja sebagai nilai dari serangkaian perilaku karyawan yang berkontribusi positif atau negatif untuk mencapai tujuan yang telah ditetapkan oleh organisasi. Kakkos dan Trivellas (2011:417) mengatakan bahwa kinerja mengacu pada perilaku yang secara langsung terlibat dalam memproduksi barang atau jasa, dan juga melibatkan perilaku yang tidak terkait langsung dengan tugas utama tetapi membentuk konteks organisasi, sosial, dan psikologis. Menurut Qadoos et al., (2015:221), kinerja karyawan berarti seorang individu berhasil melengkapi tugas yang ditetapkan oleh organisasi, sesuai dengan standar yang telah ditentukan 
bersama dengan pemanfaatan sumber daya yang efisien dalam lingkungan yang berubah-ubah.

\section{Motivasi}

Dessler (1984:328) mengatakan bahwa motivasi adalah mengetahui apa yang dibutuhkannya dan mendorongnya untuk memenuhi kebutuhannya dengan diberikan suatu ganjaran. Orang-orang yang mempunyai motivasi akan terdorong untuk berperilaku dalam cara yang mengarah pada ganjaran. Luthans dan Sommers (2005) mengemukakan bahwa motivasi adalah proses yang memberikan energi, mengubah sikap dan mempertahankan perilaku yang baik dan serta meningkatkan kinerja. Griffith et al., (2004) mengatakan bahwa motivasi juga merupakan sesuatu hal yang bisa mendorong dalam diri seseorang untuk membantu mereka dalam mencapai efektivitas dan hasil tugas yang maksimal. Karyawan yang mempunyai motivasi adalah karyawan yang produktif dan membantu organisasi untuk bertahan hidup dan berkembang. Kakkos et al., (2010) mengatakan bahwa motivasi sebagai proses psikologis yang memberikan tujuan dan arah perilaku karyawan atau sebagai dorongan internal untuk memenuhi kepuasan karyawan serta sebagai proses internal dan kekuatan eksternal yang berkaitan dengan perilaku organisasi.

\section{Kepuasan Kerja}

Lambrou et al., (2010:8) menyatakan bahwa kepuasan kerja adalah respon emosional seseorang untuk kondisi pekerjaannya. Kepuasan kerja disisi lain merupakan keadaan emosional yang menyenangkan atau positif, yang dihasilkan dari penilaian dari pekerjaan seseorang atau pengalaman kerja. Kakkos et al., (2010)mengemukakan bahwa kepuasan kerja hanya dapat didefinisikan sebagai bagaimana orang merasakan tentang pekerjaan mereka. Kepuasan kerja merupakan sikap seorang individu peduli terhadap pekerjaannya dan ini juga dikenal sebagai disposisi umum terhadap pekerjaan. Kepuasan kerja juga dapat didefinisikan sebagai keadaan yang menyenangkan atau tidak menyenangkan dari emosional seseorang karena penghargaan seseorang terhadap pekerjaannya, reaksi afektif seseorang terhadap pekerjaannya, dan sikap seseorang yang peduli terhadap pekerjaannya.

Griffith et al., (2004) mengatakan bahwa kepuasan kerja adalah respon emosional seseorang untuk kondisi pekerjaannya, sedangkan motivasi adalah kekuatan pendorong untuk mengejar dan memenuhi kebutuhan. Kepuasan kerja dan motivasi dapat bekerja sama untuk meningkatkan kinerja karyawan. Menurut Zuraidah et al., (2014), stres merupakan respon psikologis untuk tuntutan yang ada didalam diri seseorang dan tuntutan tersebut terlalu sulit untuk diatasi karena terlalu besarnya tuntutan tersebut dan melebihi kapasitas/sumber daya seseorang. Stres merupakan respon adaptif individu terhadap situasi yang dianggap sebagai hal yang menantang atau bisa jadi mengancam kesejahteraan seseorang. Ahmed dan Ramzan (2013:63) mengatakan bahwa stres adalah masalah umum dan lumayan kejadiannya di tempat kerja dan masalah ini terjadi pada semua karyawan tanpa terkecuali dan stres kerja lebih terkait dengan keluhan kesehatan dan terkait juga masalah dengan keuangan serta merupakan reaksi tubuh terhadap tuntutan lingkungan. Kakkos et al., (2010) mengatakan bahwa stres digunakan untuk menggambarkan tanggapan fisik dan 
psikologis dengan kondisi yang parah serta pengaruhnya. Stres menggambarkan kekuatan yang menyebabkan deformasi, dengan pengertian yang lebih baik dengan cara digambarkan sebagai ketegangan yang terjadi dalam tubuh. Qadoos et al., (2015:222) mengatakan bahwa stress bisa positif (Eustress) atau negatif (Distress). Eustress dapat meningkatkan kinerja dan secara positif mendorong karyawan untuk berupaya semaksimal mungkin. Stress dalam efek negatif mempengaruhi kesehatan dan kinerja. Kinerja karyawan dengan hasil negatif dipengaruhi oleh stres kerja yang berlebihan dan pada gilirannya dapat mengurangi efektivitas karyawan dalam organisasi.

\section{METODE PENELITIAN}

Penelitian ini merupakan penelitian penjelasan (explanatory research) yang akan membuktikan hubungan klausal antara variabel bebas (independent variabel) yaitu variabel motivasi, variabel kepuasan kerja dan variabel stres kerja dengan variabel terikat (dependent variabel) yaitu kinerja karyawan. Penelitian ini merupakan penelitian korelasional, yaitu penelitian yang berusaha untuk melihat apakah antara dua variabel atau lebih memiliki hubungan atau tidak, dan seberapa besar hubungan itu serta bagaimana arah hubungan tersebut (Brahmasari dan Suprayetno, 2008). Dalam penelitian ini data yang digunakan adalah data primer. Menurut Husein (2005:99), data primer adalah sumber data yang diperoleh secara langsung dari sumber asli (tidak melalui perantara). Data ini dapat berupa opini subyek (orang) secara individual/kelompok dan hasil observasi terhadap suatu benda (fisik), kegiatan/ kejadian dan hasil pengujian. Data ini diperlukan untuk mengetahui tanggapan karyawan di PT. Toyota Agung Automall Bengkulu mengenai pengaruh motivasi, kepuasan kerja dan stres kerja terhadap kinerja karyawan. Dalam penelitian ini perhitungan statistic menggunakan model analisis regresi berganda. Analisis regresi berganda adalah mengukur seberapa jauh pengaruh kepuasan kerja, motivasi kerja dan stres kerja terhadap kinerja karyawan, dengan analisa yang digunakan analisa regresi linear berganda dengan menggunakan aplikasi SPSS 17.0.

\section{HASIL PENELITIAN DAN PEMBAHASAN}

\section{Karakteristik Responden}

Dalam penelitian ini karakteristik responden yang ingin diketahui adalah berdasarkan jenis kelamin, umur, pendidikan terakhir dan pekerjaan. Untuk lebih jelasnya mengenai identitas responden tersebut dapat dilihat pada Tabel 1.

Berdasarkan Tabel 1, diketahui bahwa jumlah responden laki-laki lebih banyak dibandingkan responden perempuan. Jumlah responden laki-laki sebanyak 135 orang sedangkan responden perempuan hanya 40 orang. Struktur tugas yang terdapat di PT Toyota Agung Automall Bengkulu lebih banyak ditujukan kepada karyawan laki-laki karena di PT Toyota Agung Automall Bengkulu, karyawan sering melakukan survei dan tugas di lapangan serta turun langsung ke lokasi dari daerah kota sampai ke kabupaten yang semua itu membutukan fisik yang lebih kuat, sedangkan karyawan perempuan lebih banyak ditugaskan dibagian administrasi dan dibagian keuangan. Dari segi karakteristik usia responden, rata-rata usia yang mendominasi antara 20-29 tahun. PT Toyota Agung Automall Bengkulu didominasi 
oleh karyawan yang usianya masih tergolong muda dan produktif, sehingga lebih menunjang pekerjaan yang membutuhkan tenaga dan fisik yang masih kuat dan produktif karena sebagian besar karyawan PT Toyota Agung Automall Bengkulu sering melakukan survei lapangan dan diharapkan keberadaan mereka memberikan pengaruh positif dalam meningkatkan kinerjanya. Selanjutnya, pendidikan terakhir responden yang mendominasi adalah lulusan S1 sebanyak 128 orang. Karyawan telah memiliki tingkat pendidikan yang baik, sehingga diyakini mampu memahami dan mengerti tugas serta tanggung jawab yang dibebankan kepada mereka. PT Toyota Agung Automall Bengkulu juga membutukan karyawan-karyawan yang memang paham dibidangnya masing-masing. Oleh karena itu, PT Toyota Agung Automall Bengkulu lebih banyak membutukan lulusan S1 yang dianggap sudah memiliki kompetensi yang sesuai dengan tugas yang akan diberikan. Karyawan dengan tingkat pendidikan tersebut diharapkan dapat memengaruhi peningkatan kualitas kerja karyawan PT Toyota Agung Automall Bengkulu. Berdasarkan karakteristik masa kerja responden yang mendominasi adalah 5-10 tahun. Karyawan sudah mempunyai masa kerja yang relatif cukup lama, sehingga pengalaman kerja yang sangat baik yang selama ini telah didapatkan karyawan PT Toyota Agung Automall Bengkulu akan sangat membantu karyawan dalam melaksanakan setiap tugasnya.

Tabel 1

Karakteristik Responden

\begin{tabular}{|l|l|c|c|}
\hline No & $\begin{array}{c}\text { Karakteristik } \\
\text { Responden }\end{array}$ & Jumlah & $\begin{array}{r}\text { Persent } \\
\text { ase (\%) }\end{array}$ \\
\hline 1 & Jenis Kelamin & & \\
& a. Laki-laki & 135 orang & $77 \%$ \\
& b. Perempuan & 40 orang & $23 \%$ \\
\hline 2 & Umur & 88 orang & $50 \%$ \\
& a. $20-29$ tahun & 70 orang & $40 \%$ \\
& b. $30-39$ tahun & 15 orang & $9 \%$ \\
& c. $40-49$ tahun & 2 orang & $1 \%$ \\
\hline 3 & d. $>50$ tahun & & \\
& Pendidikan & & \\
& terakhir & a. SMA & $5 \%$ \\
& b. Diploma (D3) & 35 orang & $20 \%$ \\
& c. Sarjana (S1) & 128 orang & $73 \%$ \\
& d. Pasca Sarjana & 3 orang & $2 \%$ \\
\hline \hline 4 & Masa kerja & 61 orang & $35 \%$ \\
& a. $<5$ tahun & 104 orang & $59 \%$ \\
& b. $5-10$ tahun & 10 orang & $6 \%$ \\
\hline & c. $>10$ tahun &
\end{tabular}

Sumber: data diolah. 


\section{Hasil Analisis regresi}

Berdasarkan hasil perhitungan regresi linier berganda dengan menggunakan program SPSS 17.0, diperoleh hasil yang disajikan pada Tabel 2.

Tabel 2

\section{Hasil Uji Regresi}

\begin{tabular}{|c|c|c|c|c|c|c|c|c|}
\hline Model & \multicolumn{8}{|c|}{ Coefficients } \\
\hline \multirow[t]{2}{*}{ Model } & \multirow[t]{2}{*}{ F } & \multirow[t]{2}{*}{ Sig } & \multicolumn{2}{|c|}{$\begin{array}{c}\text { Unstandardiz } \\
\text { ed } \\
\text { Coefficients }\end{array}$} & \multirow{2}{*}{$\begin{array}{c}\begin{array}{c}\text { Standar } \\
\text { dized } \\
\text { Coeffic } \\
\text { ients }\end{array} \\
\text { Beta }\end{array}$} & \multirow[t]{2}{*}{$t$} & \multirow[t]{2}{*}{ Sig. } & \multirow[t]{2}{*}{$\begin{array}{l}\text { Adjusted } \\
\text { R Square }\end{array}$} \\
\hline & & & B & $\begin{array}{l}\text { Std. } \\
\text { Error }\end{array}$ & & & & \\
\hline $\begin{array}{l}\text { (Const } \\
\text { ant) }\end{array}$ & & & $\begin{array}{r}31,63 \\
5\end{array}$ & 4,099 & & 7,718 &, 000 & 0,450 \\
\hline $\mathrm{X} 1$ & 8,39 &, 00 & ,203 & ,066 &, 221 & 3,078 &, 002 & 0,184 \\
\hline $\mathrm{X} 2$ & 2 & 0 & ,156 & ,049 &, 229 & 3,190 &, 002 & 0,210 \\
\hline $\mathrm{X} 3$ & & &,- 253 & ,096 &,- 188 & 2.628 &, 009 & 0,126 \\
\hline
\end{tabular}

Sumber : Hasil Penelitian, 2016

$\mathrm{Y}=\mathrm{a}+\mathrm{B}_{1} \mathrm{x}_{1}+\mathrm{B}_{2} \mathrm{x}_{2}+\mathrm{B}_{3} \mathrm{x}_{3}$

$\mathrm{Y}=31,635+0,203 \mathrm{x}_{1}+0,156 \mathrm{x}_{2}+(-$

$0,253) \mathrm{x}_{3}$

\section{Penjelasan Hasil Uji Regresi}

a.) Koefisien regresi variabel motivasi terhadap kinerja karyawan PT Toyota Agung Automall Bengkulu menunjukkan bahwa ada pengaruh motivasi terhadap kinerja karyawan. Kondisi ini menunjukkan semakin tinggi motivasi di PT Toyota Agung Automall Bengkulu, tentunya akan meningkatkan kinerja karyawan.

b.) Koefisien regresi untuk variabel kepuasan kerja terhadap kinerja karyawan PT Toyota Agung Automall Bengkulu menunjukkan bahwa ada pengaruh kepuasan kerja terhadap kinerja karyawan. Kondisi ini menunjukkan jika semakin tinggi kepuasan kerja yang diberikan pada karyawan PT Toyota Agung Automall Bengkulu dapat meningkatkan kinerja karyawan.

c.) Koefisien regresi untuk variabel stres kerja terhadap kinerja karyawan PT Toyota Agung Automall Bengkulu, angka (-0.253) diatas menunjukkan bahwa ada pengaruh stres kerja terhadap kinerja karyawan tetapi berlawanan arah dengan pengaruh variabel lainnya. Kondisi ini menunjukkan bahwa jika semakin rendah stres kerja yang dialami pada karyawan PT Toyota Agung Automall Bengkulu, tentunya akan meningkatkan kinerja karyawan.

d.) Nilai adjusted $\mathrm{R}$ square pada Tabel diatas menunjukkan variabel motivasi memberikan pengaruh sebesar 0,184 atau 18,4\% sedangkan $81,6 \%$ sisanya, dipengaruhi variabel-variabel lain yang mempengaruhi kinerja yang tidak diteliti dalam penelitian ini. Variabel kepuasan kerja memberikan pengaruh sebesar 0,210 atau $21 \%$ sedangkan $79 \%$ sisanya, dipengaruhi variabel- variabel lain yang mempengaruhi kinerja yang tidak diteliti dalam penelitian ini. Variabel stres kerja 
memberikan pengaruh sebesar 0,126 atau $12,6 \%$ sedangkan $87,4 \%$ sisanya, dipengaruhi variabel-variabel lain yang mempengaruhi kinerja yang tidak diteliti dalam penelitian ini.

Berdasarkan perhitungan dengan menggunakan program SPSS 17.0, maka diperoleh hasil sebagai berikut:

1. Uji F

Berdasarkan hasil analisis regresi linier berganda pada Tabel 2, diketahui bahwa nilai sebesar 8,392 dengan nilai probabilitas $(\mathrm{sig})=0,000$. Nilai sig lebih kecil dari nilai probabilitas 0,05 atau nilai (sig) $0,000<0,05$, maka Ha diterima. Artinya, model regresi yang diuji secara keseluruhan yang terdiri atas motivasi, kepuasan kerja dan stres kerja sebagai variabel independen dan kinerja sebagai variabel dependen, telah cocok secara statistik sehingga H0 ditolak.

2. Uji T

Uji t dilakukan untuk menguji apakah variabel motivasi, kepuasan kerja dan stres kerja secara parsial berpengaruh terhadap kinerja karyawan. Hasil pengujian ini dapat dilihat melalui Tabel 2 pada setiap variabelnya.

Berdasarkan uji secara parsial $(\mathrm{t})$, maka diperoleh hasil dan penjelasan sebagai berikut:

a. Untuk variabel motivasi (X1) terdapat nilai (sig) 0,002. Menurut teori nilai (sig) lebih kecil dari nilai probabilitas 0,05 atau 0,002 <0,05, mengandung arti bahwa $\mathrm{Ha}$ diterima dan $\mathrm{HO}$ ditolak. Jadi dapat disimpulkan bahwa variabel motivasi memiliki pengaruh yang signifikan terhadap kinerja karyawan PT Toyota Agung Automall Bengkulu.

b. Nilai variabel kepuasan kerja (X2) dengan nilai signifikansi 0,002 $<0,05$ menunjukkan Ha diterima dan HO ditolak. Jadi dapat disimpulkan variabel kepuasan kerja berpengaruh signifikan terhadap kinerja karyawan PT Toyota Agung Automall Bengkulu.

c. Variabel stres kerja (X3) dengan tingkat signifikansi 0,009 $<0,05$ menunjukkan bahwa Ha diterima dan $\mathrm{H} 0$ ditolak. Jadi dapat disimpulkan variabel stres kerja secara parsial berpengaruh signifikan terhadap kinerja karyawan PT Toyota Agung Automall Bengkulu.

\section{Pembahasan Hasil Penelitian}

\section{Pengaruh Motivasi, Kepuasan Kerja dan Stres Kerja Terhadap Kinerja Karyawan PT Toyota Agung Automall Bengkulu}

Variabel motivasi, kepuasan kerja dan stres kerja secara statistik berpengaruh terhadap kinerja karyawan PT Toyota Agung Automall Bengkulu. Motivasi yang diberikan dan kepuasan kerja yang dirasakan oleh seluruh karyawan mengakibatkan karyawan akan terus mencoba untuk lebih baik lagi dalam bekerja untuk memenuhi target perusahaan. Karyawan akan mengontrol stres kerjanya agar tidak menganggu konsentrasi dalam bekerja yang nantinya jika tidak dikontrol akan berakibat terhadap kinerja yang diperoleh kedepannya. Hasil penelitian ini juga sejalan dengan pendapat yang disampaikan Kakkos et al.,(2010) yang mengatakan bahwa kinerja karyawan dapat dipengaruhi oleh beberapa kondisi seperti kepuasan 
kerja, motivasi dan stres. Motivasi yang diberikan kepada karyawan akhirnya dapat membantu karyawan meningkatkan kinerjanya dan mencapai tujuan yang ditetapkan. Jika karyawan peduli terhadap pekerjaannya dan cenderung senang terhadap pekerjaannya, karyawan tersebut merasakan kepuasan kerja dan pada akhirnya dapat meningkatkan kinerja. Stres juga memiliki pengaruh yaitu terlalu banyak memiliki tekanan maka karyawan nantinya memiliki implikasi stres seperti keterasingan mental dan berdampak pada kinerja individu, juga penghancur semangat tim, ketidakpuasan kerja bahkan mengundurkan diri dari pekerjaan. Begitu pula dengan hasil penelitian Riyadi (2015) yang menunjukkan bahwa variabel motivasi, kepuasan kerja, dan stres kerja memiliki pengaruh positif dan negatif serta signifikan terhadap kinerja.

\section{Pengaruh Motivasi Terhadap Kinerja Karyawan PT Toyota Agung Automall Bengkulu}

Variabel motivasi secara statistic berpengaruh terhadap kinerja karyawan PT Toyota Agung Automall Bengkulu. Motivasi menyebabkan karyawan akan terus mencoba untuk lebih baik lagi dalam bekerja baik itu untuk dirinya sendiri maupun bagi perusahaan. Kakkos dan Trivellas (2011) mengatakan bahwa hubungan yang ada diantara unsur-unsur motivasi dan kinerja didominasi oleh kejelasan teoritis dan hasil empiris meyakinkan dan membuktikan bahwa motivasi berpengaruh terhadap kinerja karyawan. Saleem et al., (2010:215) mengatakan bahwa motivasi memiliki efek positif yang kuat pada kinerja dan motivasi diperlukan oleh karyawan untuk memicu semangat dalam bekerja dan membangkitkan kesenangan karyawan dalam mengerjakan pekerjaannya. Motivasi berpengaruh positif terhadap kinerja karyawan, yang artinya jika motivasi meningkat mengakibatkan kinerja akan meningkat. Begitu pula dengan hasil penelitian Kakkos dan Trivellas (2011) yang menunjukkan bahwa variabel motivasi memiliki pengaruh positif dan signifikan terhadap kinerja.

\section{Pengaruh Kepuasan Kerja Terhadap Kinerja Karyawan PT Toyota Agung Automall Bengkulu}

Variabel kepuasan kerja secara statistik berpengaruh terhadap kinerja karyawan PT Toyota Agung Automall Bengkulu. Dapat disimpulkan bahwa dengan kepuasan kerja yang tinggi menyebabkan karyawan akan lebih baik dalam bekerja dan lebih banyak pekerjaan yang terselesaikan sehingga hasil pekerjaannya sesuai yang telah ditargetkan oleh perusahaan. Shahu dan Gole (2008) mengatakan bahwa ada efek dari pengaruh kepuasan kerja terhadap kinerja maka kepuasan kerja harus dipertimbangkan oleh organisasi sebagai rencana penting dalam rangka meningkatkan kinerja karyawan, dan jika kepuasan kerja rendah maka kinerja mereka cenderung menurun. Velnampy (2008) menyimpulkan ada pengaruh positif kepuasan kerja terhadap kinerja karyawan seperti meningkatnya keterlibatan kerja dan kinerja yang lebih tinggi, membuat orang merasa lebih puas serta berkomitmen untuk organisasi. Kepuasan kerja dan kinerja karyawan terikat dalam satu siklus dan saling bergantung. 


\section{Pengaruh Stres Kerja Terhadap Kinerja Karyawan PT Toyota Agung Automall Bengkulu}

Variabel stres kerja secara statistic berpengaruh terhadap kinerja karyawan PT Toyota Agung Automall Bengkulu. Dapat disimpulkan bahwa stres kerja dapat menurunkan kinerja karyawan karena pengaruhnya adalah negatif. Qadoos et al. ( 2015:222) mengatakan stress bisa positif (Eustress)atau negatif (Distress). Eustress dapat meningkatkan kinerja dan secara positif mendorong karyawan untuk berupaya semaksimal mungkin. Stress dalam efek negatif mempengaruhi kesehatan dan kinerja. Kinerja karyawan dengan hasil negatif dipengaruhi oleh stres kerja yang berlebihan dan pada gilirannya mengurangi efektivitas karyawan dalam organisasi. Sui (2003) mengatakan bahwa stres kerja telah menjadi efek negatif dan stres kerja hal yang tidak diinginkan oleh karyawan. Stres kerja akan menaikkan biaya pengobatan, tingkat absensi dan perpindahan yang tinggi, dan kinerja yang lebih rendah. Telah diketahui bahwa stres kerja berpengaruh negatif terhadap kinerja karyawan, yang artinya jika stres kerja meningkat maka kinerja akan menurun. Begitu pula dengan hasil penelitian Ahmed dan Ramzan (2013) yang menyatakan adanya pengaruh antara stres kerja dengan kinerja karyawan, artinya semakin meningkat pengaruh stres kerja karyawan maka semakin menurunnya kinerja karyawan.

\section{Kesimpulan Dan Saran}

\section{Kesimpulan}

Berdasarkan hasil penelitian dan pembahasan sebagaimana telah dijelaskan sebelumnya, dapat ditarik kesimpulan:

1. Jika motivasi dan kepuasan kerja meningkat maka kinerja karyawan PT Toyota Agung Automall Bengkulu juga akan meningkat. Jika stres kerja menurun maka kinerja karyawan PT Toyota Agung Automall Bengkulu akan meningkat.

2. Motivasi mempunyai pengaruh terhadap kinerja karyawan PT Toyota Agung Automall Bengkulu.

3. Kepuasan kerja mempunyai pengaruh terhadap kinerja karyawan PT Toyota Agung Automall Bengkulu.

4. Stres kerja memiliki pengaruh terhadap kinerja karyawan PT Toyota Agung Automall Bengkulu. Artinya jika stress kerja yang dialami karyawan rendah maka kinerja karyawan akan meningkat.

\section{Saran}

Berdasarkan hasil penelitian yang telah dilakukan di PT Toyota Agung Automall Bengkulu, maka saran yang dapat dijadikan sebagai bahan pertimbangan pihak PT Toyota Agung Automall Bengkulu adalah sebagai berikut:

1.Branch Manager disarankan melaksanakan program pelatihan dan pengembangan untuk meningkatkan kemampuan karyawannya agar nantinya lebih teliti dan berhati-hati dalam bekerja.

2. Perusahaan disarankan memberikan motivasi untuk karyawan dalam titik maksimum seperti halnya kepuasan kerja, sehingga karyawan menganggap perusahaan sangat peduli terhadap mereka dan karyawan lebih maksimal lagi untuk 
meningkatkan kinerja mereka agar kinerja perusahaan juga meningkat.

3. Perusahaan sebaiknya tidak terlalu memforsir tenaga karyawan dan juga tidak terlalu memberikan tekanan-tekanan yang terlalu berlebihan terhadap karyawan karena karyawan juga manusia biasa yang ada batas kemampuannya dalam menghadapi setiap permasalahan yang dihadapi.

\section{DAFTAR PUSTAKA}

Achim, I.M. et al. 2013. The Importance of Employee Motivation To Increase Organizational Performance. Annales Universitatis Apulensis. 2 (15). 685691.

Ahmed, A. and Ramzan, M. 2013. Effects of Job Stress on Employees Job Performance A Study on Banking Sector of Pakistan. IOSR Journal of Business and Managemet. 11 (6). 61-68.

Akhmad Subekhi dan Mohammad Jauhar. 2012. Pengantar Manajemen Sumber Daya Manusia. Jakarta :Prestasi Pustaka.

Anderson, R. 2003. Stress at Work : the Current Perspective. The Journal of The Royal Society for The Promotion on Health. 123 (12). 8191.

Arshadi, N. and Damiri, H. 2013. The Relationship of Job Stress with Turnover Intention and Job Performance: Moderating Role of OBSE. International Journal Social and Behavioral Sciences. 84. $706-710$.

Azar, M and Shafighi, A.A. 2013. The Effects of Work Motivation on Employees' Job Performance. International Journal of Academic Research in Business and Social Science. 3 (19). 432-445.

Bajpai, J.V. et al. 2015. A Study of Impact of Work Stress on Job Satisfaction of Employees Working in Indian Banking Sector International Journal of Business Quantitative Economics and Applied Management Research. 1(11). 27-32.

Bangun, Wilson. 2012. Manajemen Sumber Daya Manusia. Jakarta: Penerbit Erlangga.

Bousinakis, D. and Halkos, G. 2010. The effect of stress and satisfaction on productivity. International Journal of Productivity and Performance Management. 59 (5). 415-431.

Cong, N.N. and Van, D.N. 2013. Effects of Motivation and Job Satisfaction on Employees' Performance at Petrovietnam Nghe an Construction Joints Stock

Corporation(PVNC). International Journal of Business and Social Science. 4 (6). 212217.

Cole, Shawn et al. 2009. Smart Money: The Effect of Education, Cognitive Ability, and Nancial Literacy on Nancial Market Participation. Journal Education of Management. 9 (71). 15-21.

Dessler, Gary. 1984. Manajemen Personalia. Edisi Ketiga. Jakarta:Penerbit Erlangga. 2000. Manajemen Sumbe Daya Manusia. Jakarta : BumAksara.

Fahmi, Irham. 2011. Manajemen Kinerja Teori Dan Aplikasi. Bandung: Penerbit Alfabeta.

Ghozali, Imam. 2005. Aplikasi Analisis Multivariate Dengan Program SPSS. Semarang : Badan Penerbit Universitas Diponegoro. 
Gibson dkk. 1985. Organisasi. Edisi Kelima. Jakarta : Penerbit Erlangga.

Griffith, J. 2004. The Relation of Principal Transformational Leadership to School Staff Job Satisfaction, and School Performance. Journal of Education Administration. 42 (3).333-356.

Groen, B.A. et al. 2012. Why do employees take more initiatives to improve their performance after codeveloping performance measures? A field study. Management Accounting Research. 120-141.

Hameed, A and Waheed, A. 2011. Employee Development and Its Affect on Employee Performance a Conceptual Framework. International Journal of Business and Social Science. 2 (13). 224230.

Handoko, T.Hani. 2001. Manajemen Personalia dan Sumberdaya Manusia. Edisi Lima Belas. Yogyakarta : BPFE Yogyakarta.

Hasibuan, Malayu S.P. 2013. Manajemen Sumber Daya Manusia. Jakarta : PT Bumi Aksara.

Ida Ayu Brahmasari. 2004. Pengaruh Variabel Budaya Perusahaan terhadap Komitmen Karyawan dan Kinerja Perusahaan Kelompok Penerbitan Pers Jawa Pos. Surabaya. Fakultas Ekonomi Universitas Airlangga.

Ida Ayu Brahmasari dan Agus Suprayetno. 2008. Pengaruh Motivasi Kerja, Kepemimpinan dan Budaya Organisasi Terhadap Kepuasan Kerja Karyawan serta Dampaknya pada Kinerja Perusahaan (Studi Kasus pada PT. Pei Hai Internasional Wiratama Indonesia). Jurnal Manajemen dan Kewirausahaan. 10 (2). 124-135.

Istijanto. 2005. Riset Sumber Daya Manusia. Jakarta : PT Gramedia Pustaka Utama.

Ivancevich, John M dkk. 2005. Perilaku Dan Manajemen Organisasi. Jakarta : PT Erlangga.

Kadarisman. 2012. Manajemen Pengembangan Sumber Daya Manusia. Jakarta : PT Raja Grafindo.

Kakkos, N. et al. 2010. Exploring the Link Between Job Motivation, Work Stress And Job Satisfaction. Evidence From The Banking Industry. 7th International Conference on Enterprise Systems, Accounting and Logistics. 2. 211230.

Kakkos, N. and Trivellas P. 2011. Exploring the Link Between Job Motivation, Work Stress And Job Performance. Evidence From The Banking Industry. 8th International Conference on Enterprise Systems, Accounting and Logistics. 22. 409428.

Khalid, K. et al. 2011. The Impact of Rewards and Motivation on Job Satisfaction in Water Utility Industry. Intrenational Conference on Financial Management and Economics. 11. 35-41.

Lambrou, P. et al. 2010. Motivation and Job Satisfaction Among Medical and Nursing Staff in A Cyprus Public General Hospital. Human Resource for Health. 1-9.

Luthans, K.W. and Sommers, S.M. 2005. The Impact of High Performance Work on Industry Level Outcomes. Journal of Managements. 17 (3). 327-345.

Logan, M.S. and Ganster, D.C. 2005. An experimental evaluation of a control intervention to alleviate job-related stress. Journal of Management. 31 (1). 90-107.

Mansoor, M. et al. 2011. The Impact of Job Stress on Employee Job Satisfaction, A Study on TeleCommunication Sector of Pakistan. Journal of Business Studies Quarterly. 2 (3). 50-56. 
Muhammad, J. et al. 2011. Effect of Job Stress on Job Performance and Job Satisfaction. Interdisciplinary Journal of Contemporary Research in Business. 3 (7). 453-465.

Rivai, Veithzal. 2003. Kepemimpinan dan Perilaku Organisasi. Jakarta : PT Raja Grafindo Persada.

Robert L. Mathis dan John H. Jackson. 2002. Manajemen Sumber Daya Manusia. Jakarta : Penerbit Salemba.

Robbin, Stephen P. 2002. Perilaku Organisasi. Jakarta : Penerbit Erlangga.

Robbins, Stephen P. dan Judge, Timothy A. 2013. Perilaku Organisasi. Jakarta : Penerbit Salemba Empat.

Rofiaty. 2012. Inovasi Dan Kinerja (Knowledge Sharing Behaviour Pada UKM). Malang : UB Press.

Rose, M. 2003. Good Deal, Bad Deal? Job Satisfaction in Occupations. Work Employment Society. 17. 503-508.

Saleem, R. et al. 2010. Effect of Work Motivation on Job Satisfaction in 16 Mobile Telecommunications Service Organization of Pakistan. International Journal of Business and Managemet. 5 (11). 213-222.

Siagian, Sondang. 2010. Manajemen Sumber Daya Manusia. Jakarta : PT Bumi Aksara.

1995. Teori Motivasi Dan Aplikasinya. Jakarta : PT Rineka Cipta.

Stamper, L.C. and Johlke, C.M. 2003. The Impact of Perceived Organizational Support on the Relationship Between Boundary Spanner Role Stress and Work Outcomes. Journal of Managerial. 29. 569.

Supranto, J. 2000. Statistik Teori dan Aplikasi Edisi Keenam. Jakarta : Erlangga.

Sugiyono. 2011. Metode Penelitian Kuantitatif, Kualitatif dan R \& D. Edisi Ketigabelas. Bandung : Penerbit Alfabeta.

Umar, Husein. 2005. Riset Sumber Daya Manusia Dalam Organisasi. Jakarta : PT Gramedia Pustaka Utama.

Wibowo. 2013. Manajemen Kinerja. Edisi Ketiga. Jakarta : PT Raja Grafindo Persada.

Veithzal Rivai dan Sagala, Ella Jauvani. 2011. Manajemen Sumber Daya Manusiauntuk Perusahaan : Dari Teori ke Praktik. Edisi Kedua. Jakarta : PT Raja Grafindo Persada.

Velnampy, T. 2008. Job Attitude and Employees Performance of Public Sector Organization in Jaffna 17 District, Sri Lanka. GITAM Journal of Management. 6 (2). 66-73.

Wang, H.M. and Feng, W.W. 2003. Review on Employee Job Satisfaction. Commercial

Research. 9 (12). 43-50 Wright, T.A. and Bonett, D.G. 2007. Job Satisfaction and Pshychological Well-Being as Nonaddictive Predictors of Workplace Turnover. Journal of Management. 33 (1). 141-160.

Yaslioglu, M et al. 2013. An Empirical Research on the Relationship between Job Insecurity, Job Related Stress and Job Satisfaction in Logistics Industry. International Journal of Social and Behavioral Sciences. 99(1). 332-338.

Zuraidah, R. et al. 2014. The Impact of Job Stress to Job Satisfaction among Engineers : A Literature Preview. 4th International Conference on Industrial Engineering and Operation Management . 2418-2425. 